\title{
Outsourcing and Innovative Activity of the Companies From the Visegrád Group
}

\author{
Marek Tomaszewski \\ University of Zielona Góra, Zielona Góra, Poland
}

\begin{abstract}
Outsourcing is a change from horizontal cooperation (coopetition) to a vertical one. That is, the company, which up to now could be considered as a competitor, changes into a supplier. It is worth remembering that the company that is to become a supplier can either create a new one or be an already existing one. This article is based on empirical data coming from the companies from the Visegrád Group that is Poland, the Czech Republic, Slovakia, and Hungary. The results presented here imply that outsourcing has a stimulating effect on innovative activity of a company both in terms of investment and implementation aspects. Also, innovative activity, in its investment and implementation aspects, positively influences the occurrence of outsourcing. This confirms the existence of feedback among these variables. It is worth noting however, that the probability of innovative activity among the companies using outsourcing is higher than the probability of outsourcing among the companies that are innovatively active. It seems that the influence of outsourcing on innovative activity is stronger than the influence of innovative activity on outsourcing.
\end{abstract}

Keywords: outsourcing, innovative activity, Visegrád Group

\section{Introduction}

Faced with the realities of globalisation, small and medium businesses cannot rely solely on their own knowledge resources (Carayannis, 1999, pp. 141-161; Chesbrough, 2003; Desouza, Awazu, \& Jasimuddin, 2005, pp. 16-19; Hitt, Ireland, \& Lee, 2000, pp. 231-246). These companies realise that in order to achieve success, it is necessary to collaborate with external entities with regards to knowledge exchange, more effective ways of using the available resources or realising joint ideas. For small and medium companies facing the realities of globalisation, the solution is to focus on a given market niche, with the prospects of using highly specialised knowledge and production potential. To that end, companies must continuously improve their key skills and collaborate with external partners. Combining these two elements (specialised resources at the company's disposal and partners' knowledge) enables companies to increase their innovative activity (Sull, 1999, pp. 42-52).

Complementing assets, broader and improved catalogue of products or services can increase the range of a company, improving its competitiveness (Herrmann, Tomczak, \& Befurt, 2006, pp. 20-43; Benner \& Tushman, 2003, pp. 238-256; March, 1991, pp. 71-87). One should keep in mind that in today's world, global-scale

Marek Tomaszewski, Ph.D., Department of Innovation and Entrepreneurship, University of Zielona Góra, Poland.

Correspondence concerning this article should be addressed to Marek Tomaszewski, Podgórna Street 50, 65-246 Zielona Góra, Poland. E-mail: m.tomaszewski@wez.uz.zgora.pl. 
innovations are of interdisciplinary character. A specialist in a given field is able to improve only the solutions that fall within that field. This means that small and medium companies by themselves do not have the potential to innovate on a global scale. This forces the necessity to cooperate with the companies from other sectors of the market. Outsourcing is one of the forms of cooperation among companies.

\section{Literature Review}

There are various definitions of outsourcing and outsourcing companies in the literature, for example, one of the definitions states that the outsourcing company is an entity that has the possibility of offering and performing non-strategic activities and business processes and that has the human resources required for production or services. Offering services or production of goods is a result of agreement with customer and is aimed at achieving a competitive edge by the customer (Espino-Rodriguez \& Padro-Robaina, 2006, pp. 49-70). Yet another definition of outsourcing emphasises the fact that the entirety of a part of company's activity is being transferred to an external supplier (Barthélemy, 2003, p. 87). Within the transactional costs economics, outsourcing is understood as replacing the notion of "perform/do" with "buy" (Grossman \& Helpman, 2005, pp. 135-159). According to yet another definition, outsourcing is the ordering of the products or services from the sources that are external to the company (Lankford \& Parsa, 1999, pp. 310-316).

From an analysis of the above definitions of outsourcing in the context of innovative activity of companies, one notices that companies can divide their organisational activities into three parts: R\&D, production, and distribution (Quinn, 2000, pp. 13-28). Modern and innovatively pro-active companies focus on R\&D, whereas production and distribution are transferred to the companies that specialise in them. In this context, outsourcing can be defined as transferring either entire modules of company's activities or just the functional aspects of company's operations (e.g. job recruitment and downsizing processes) to an external entity, which becomes a supplier.

The main advantages of outsourcing are cost control and cost reduction (Jain \& Natarajan, 2011, p. 296; Fisher, Hirschheim, \& Jacobs, 2008, pp. 165-78). Cost reduction is made possible by the emerging scale effect in outsourcing companies that are characterised by a highly specialised production processes (Ang \& Cummings, 1997, pp. 235-256). Additional advantages of outsourcing can be related to:

(1) extending the scope of competencies of management and access to new technological knowledge that has been unavailable before the company that outsources (Lacity \& Willcocks, 1998, pp. 363-408);

(2) lowering the risk and technological uncertainty (McLellan, Marcolin, \& Beamish, 1995, pp. 299-321);

(3) improvement in terms of company's institutional aspects, including organisational structure, management style, and organisational complementatrity of the project (Milgrom \& Roberts, 1995, pp. 179-208; Loh \& Venkatraman, 1992, pp. 334-78; Hu, Saunders, \& Gebelt, 1997, pp. 288-301);

(4) general improvement in company's effectiveness, improvements in customer service and other strategic motifs (Willcocks, 2010, pp. 62-66; Gulla \& Gupta, 2009, pp. 25-40).

Apart from these advantages of implementation and realisation of outsourcing, there are possible problems related to opportunistic behaviours. The notion of "opportunism" is explained in the transactional costs theory and other institutional theories such as: contractual theory of companies and theory of agencies. Williamson (1975, p. 255) defined opportunistic behaviour as self-interest seeking with guile. He claimed that the resourceful man is a devious and subtle creature when he tries to gain additional benefits. In time, this idea was modified. Then, Williamson (1985, p. 47) defined the notion of "opportunism" in categories of incomplete or 
distorted information aimed to mislead, distort the situation, or disrupt a given process. The final aim of all these actions is obviously to gain benefits without others noticing the harmfulness.

Opportunistic behaviour causes the collaborators to lose interest, increasing the risk related to the undertaken joint endeavour. Limiting this risk is related to increase in costs related to monitoring and motivating partners to deeper engage in collaboration.

The opportunistic behaviour can occur in relation to both external and internal entities. In case of internal entities, the opportunistic behaviour can occur in employees fearing the loss of jobs related to transferring the production to an external entity (Yang, Kim, Nam, \& Min, 2007, pp. 3769-3778). The opportunistic behaviour related to the external entity is related to the loss of control over the production process (Quinn \& Hilmer, 1994, pp. 43-55). A disadvantageous choice of a supplier can result in deliveries made not on time, product of compromised quality, and problems with delivering services (Aubert, Dussault, Patry, \& Rivard, 1999). These problems are directly related to the increase of risk of client company reputation worsening. The choice of the right supplier is especially important in not fully developed supplier market, as could be the case in developing countries (Adeleye, Annasingh, \& Nunes, 2004, pp. 167-180). The loss of internal competencies and worsening of innovative potential level in terms of enhancing innovation is an equally important problem connected to outsourcing.

The next group of problems related to the possible opportunistic behaviour on the side of the outsourcing supplier company is connected with the problem of its access to classified information. The risks related to an access for an external partner to classified information are even more substantial than any other risks related to outsourcing (Khalfan, 2004, pp. 29-42).

Summing up, one can claim that inappropriate relations with the outsourcing supplier company are one of the biggest threats related to outsourcing. Inappropriate relations can cause the customer company more harm than good and undermine its reputation (Baldwin, Irani, \& Love, 2001, pp. 15-24).

\section{Methodical Aspects of Research}

The empirical data on the basis of which made the calculations and interpreted the results were obtained during the fourth round of the Business Environment and Enterprise Performance Survey (BEEPS) taken between 2008-2009 for European Bank for Reconstruction and Development and the Wold Bank. It reached 1,349 companies from the Visegrád countries. Table 1 presents the structure of these companies, split into countries.

Table 1

Characteristics of the Researched Companies From the Visegrád Countries

\begin{tabular}{llcccc}
\hline \multirow{2}{*}{ No. } & country & \multicolumn{4}{c}{ Number of companies } \\
\cline { 3 - 6 } & & total & Manufacturing companies & Retail companies & Other servicing companies \\
\hline 1 & Czech Republic & 250 & 94 & 90 & 66 \\
2 & Poland & 533 & 172 & 175 & 186 \\
3 & Slovakia & 275 & 86 & 97 & 92 \\
4 & Hungary & 291 & 103 & 105 & 83 \\
Total & & 1,349 & 455 & 467 & 427 \\
\hline
\end{tabular}

Source: own analysis based on BEEPS 2009 data.

Three types of companies: processing, servicing, and industrial companies took part in the survey. 
Additionally, all the companies had to employ at least five employees full-time. Many kinds of state-run enterprises, including army, police, health service, and education were excluded. The survey covered companies from the following sectors, according to ISIC Rev 3.1:

Group D - companies involved in manufacturing;

Group F-companies involved in construction;

Groups $\mathrm{G}$ and $\mathrm{H}$ - companies involved in wholesale and retail trade, repair of motor vehicles, motorcycles and personal and household goods, hotels and restaurants (services);

Group I-companies involved in transport, storage, and communication.

The survey did not cover the companies from the groups: J and K (financial intermediation, real estate) with the sole exception of the subsector 72: computer and related activities. Moreover, the survey did not include companies that are involved in farming and mining (retrieved from http://www.enterprisesurveys.org/Methodology).

The static survey concerns the period 2006-2008, which is consistent with the methodological standards described in the Oslo Manual (2005). In order to accept or reject the research hypothesis, the explanatory variable is defined as the fact of outsourcing occurring in a company. As the dependent variables took the occurrence of the following in a company: (a) investment activity, (b) R\&D activity, (c) introduction of new products, (d) product update, (e) international quality certificates awarded for the products. In order to determine if there is a feedback between outsourcing and innovative activity swapped the explanatory and dependent variables in section five of this article, the above mentioned attributes of innovative activity become explanatory variables, whereas the fact of outsourcing occurring in a company becomes the dependent variable.

The above variables mirror the questions asked during the survey undertook for the EBRD and the World Bank. These were the closed questions, meaning that a list of possible answers was provided to choose.

The accepted explanatory and dependent variables were dichotomous, meaning that they could be assigned either 0 or 1 . In case of variables describing innovative activity, this means that either a company implemented a given innovative process (the variable was assigned 1) or it did not (in such cases the variable was assigned 0 ). The dichotomous character of explanatory and dependent variables means that some of the most popular modelling techniques cannot be used, including multiple regressions.

Estimating the model parameters during the construction of probit model was done using the maximum likelihood estimation. Basic assumptions of this method are based on the likelihood function. It is applied to models with an additive random component and assuming its normal distribution (Welfe, 2003, p. 76).

The Statistica suite has been used to perform calculations presented in this article. For all the Visegrád countries, 40 models were constructed, 30 of which were statistically significant. A structural form of representing models was used, given that the considered models only take one factor into account in interpreting the analysed relations.

The sign applied to a given parameter is the key. The plus sign means that the probability of a given innovative activity in a company relying on outsourcing is greater than that in the companies that do not use outsourcing. The minus sign means that the probability of a given innovative activity in a company relying on outsourcing is lower than that in the companies that do not use outsourcing.

For the purposes of this article, the following research hypotheses are defined:

Hypothesis 1: Outsourcing has a stimulating effect on investment and implementation aspect of innovative activities of companies from the Visegrád countries; 
Hypothesis 2: The relation between outsourcing and innovative activity can be defined as feedback;

Hypothesis 3: Outsourcing is very closely connected to efforts invested in improving the company's products.

\section{Research Results and Analysis}

\section{Outsourcing Influence on the Investment Aspect of Innovative Activity of Companies}

Within the investment aspect of innovative activity of the Visegrád companies, an influence of outsourcing on investment and $R \& D$ has been analyzed. The resulting probit models are summed up in the following Table 2 and Table 3.

Table 2

Parameter Values With Explanatory Variable "Occurrence of Outsourcing in a Company" in the Probit Models Describing the Investment Activity of Companies From the Visegrád Countries

\begin{tabular}{lllllllll}
\hline Company's location & parameter & $s$ & $t$ & $p>|z|$ & $p_{1}$ & $p_{2}$ & $x^{2}$ & $p$ \\
\hline Czech Republic & +0.46 & 0.22 & 2.15 & 0.03 & 0.71 & 0.53 & 4.74 & 0.03 \\
Poland & +0.49 & 0.18 & 2.74 & 0.01 & 0.79 & 0.62 & 7.90 & 0.00 \\
Slovakia & +0.77 & 0.23 & 3.29 & 0.00 & 0.82 & 0.56 & 11.78 & 0.00 \\
\hline
\end{tabular}

Source: own analysis based on BEEPS 2009 data.

where:

$p$ - the standard error,

$t$-student's $T$-statistic for the parameter,

$p>|z|$ - probability the parameter is not significant,

$p_{1}$ - probability of a given event in the analysed group of companies,

$p_{2}$ - probability of a given event in the remaining groups of companies,

$x^{2}$ - Chi-squared test,

$p$ - probability of non-significance of the model.

It follows from the above table that outsourcing in companies had a stimulating effect on investment activity of these companies. Probability of investment in companies that used outsourcing ranged, depending on the country, from 0.71 to 0.82 (Table 2). It was from $27 \%$ to $46 \%$ greater than the probability of investment in companies that did not use outsourcing. The Slovakian companies using outsourcing have the highest probability of investment, whereas the Czech companies using outsourcing have the lowest.

Outsourcing all production or its part to an external company means that some of the resources used are being freed. The freed resources can be moved to new areas of the company's activity or to the already exploited areas but generating greater rate of return. In both cases, it was necessary to adapt the freed resources to the new needs, motivating investment. There also was a third possibility - the assets that were freed as the result of outsourcing had been sold. As the result of it, the resources could be invested in a completely new enterprise.

The probability of R\&D activities was also markedly greater for companies that were using outsourcing. It equalled, depending on the country of origin, 0.45 to 0.55 (Table 3) and was from $74 \%$ to $139 \%$ greater than the probability of $\mathrm{R} \& \mathrm{D}$ activities for the companies that did not use outsourcing. Comparing the countries, one notices that the Polish companies had the highest probability of R\&D activity, whereas the Hungarian ones had the lowest. 
Table 3

Parameter Values With Explanatory Variable "Occurrence of Outsourcing in a Company" in the Probit Models Describing the R\&D Activity of the Companies From the Visegrád Countries

\begin{tabular}{lllllllrl}
\hline Company's location & parameter & $s$ & $t$ & $p>|z|$ & $p_{1}$ & $p_{2}$ & $x^{2}$ & $p$ \\
\hline Czech Republic & +0.58 & 0.21 & 2.76 & 0.01 & 0.47 & 0.25 & 7.59 & 0.01 \\
Poland & +0.87 & 0.16 & 5.36 & 0.00 & 0.55 & 0.23 & 28.97 & 0.00 \\
Slovakia & +0.52 & 0.21 & 2.50 & 0.01 & 0.47 & 0.27 & 6.22 & 0.01 \\
Hungary & +0.66 & 0.20 & 3.29 & 0.00 & 0.45 & 0.21 & 10.73 & 0.00 \\
\hline
\end{tabular}

Source: own analysis based on BEEPS 2009 data.

Outsourcing in a company made it possible to focus on research related to improvements of the manufactured goods or introducing new ones. Freeing financial or personal resources from the responsibilities related to the manufacturing process meant that these can now be used to the existing or newly created R\&D department. Moreover, the employees previously working in production departments had the highest qualifications in terms of supervising the production process in the company to which it had been outsourced. By supervising the production process, these employees had a chance of comparing the two ways of implementing the production process: in their home company and in the new one. This knowledge could then be used in their home company to improve the production processes for other products.

\section{Outsourcing Influence on the Implementation Aspect of Innovative Activity of Companies}

Within the implementation aspect of innovative activity, the following elements were analysed: introduction of a new product, modernisation of an existing product, and effort aimed at obtaining quality certificates for products.

Only one statistically significant probit model has been obtained in terms of influence of outsourcing on new product implementation. This model has been calculated for Polish companies. It looks as follows:

$$
Y=0.68 x \times 0.12
$$

where:

$$
\begin{aligned}
& s=0.18 \\
& t=3.81 \\
& p>|z|=0.00 \\
& p_{1}=0.45 \\
& p_{2}=0.21 \\
& x^{2}=15.53 \\
& p=0.00
\end{aligned}
$$

From the above model it follows that the probability of implementing new product in companies that use outsourcing equals 0.45 and is markedly greater (nearly two-times greater) from the probability of implementing new product in companies that do not use outsourcing.

The table below depicts the influence of outsourcing on the probability of activity aimed at improving the product that is being manufactured. As a result of the calculations, three statistically significant models were obtained, presented in Table 4.

The probability values in the table indicate that, especially in the Czech Republic, there is almost a certainty that the companies that use outsourcing at the same time take up actions aimed at improving the 
manufactured products. The probability that the companies using outsourcing modernise manufactured products equals, depending on location, from 0.84 (Slovakia) to 0.98 (the Czech Republic). The probability of modernisation in the already manufactured products in companies that used outsourcing was from $25 \%$ to $40 \%$ greater than the probability of modernisation in the already manufactured products in companies that did not use outsourcing.

Table 4

Parameter Values With Explanatory Variable "Occurrence of Outsourcing in a Company" in the Probit Models Describing the Activity Aimed at Improving the Manufactured Product at the Companies From the Visegrád Countries

\begin{tabular}{lllllllll}
\hline Company's location & parameter & $s$ & $t$ & $p>|z|$ & $p_{1}$ & $p_{2}$ & $x^{2}$ & $p$ \\
\hline Czech Republic & +1.46 & 0.43 & 3.44 & 0.00 & 0.98 & 0.70 & 20.37 & 0.00 \\
Poland & +0.70 & 0.21 & 3.31 & 0.00 & 0.90 & 0.72 & 12.49 & 0.00 \\
Slovakia & +0.61 & 0.24 & 2.52 & 0.01 & 0.84 & 0.66 & 6.87 & 0.01 \\
\hline
\end{tabular}

Source: own analysis based on BEEPS 2009 data.

The positive relation between outsourcing and an introduction of new or improved products had many reasons. Firstly, the companies that use outsourcing belong to the group that more easily accept changes and are more prone to risk taking (Argyres \& Liebeskind, 1999, pp. 49-63). These very features are characteristic of people, who are more innovative, hence more prone to introduce new products or modernise the already manufactured ones. Secondly, the companies that use outsourcing have more free resources at their disposal and are able to more easily obtain additional knowledge. This means that these companies are able to faster overcome the problems related to the introduction or improvement in products, than the companies, which do not use outsourcing (Levinthal \& March, 1993, pp. 95-113). Thirdly, the companies that do not use outsourcing have higher "searching for knowledge" costs and higher knowledge-adaptation costs (Foray, 2004). This in turn makes the realisation of activities related to innovation more difficult. Fourthly, the companies that use outsourcing have a more developed partner network than those, which do not use outsourcing. It can be noted that having a better developed partner networks positively influences the level of innovative activities in a company (Silver, 1984). Finally, an analysis of results from the "technological dialogue" between supplier and client also has a positive influence on the innovative activity (Christensen, Verlinden, \& Westerman, 2002, pp. 955-993).

The following Table 5 presents the probit models depicting the relation between outsourcing and implementing international quality certificates.

Tabela 5

Parameter Values With Explanatory Variable "Occurrence of Outsourcing in a Company" in the Probit Models Describing the Activity Aimed at Implementing International Quality Certificates at Companies From the Visegrád Countries

\begin{tabular}{lllllllrr}
\hline Company's location & parameter & $s$ & $t$ & $p>|z|$ & $p_{1}$ & $p_{2}$ & $x^{2}$ & $p$ \\
\hline Czech Republic & +0.53 & 0.21 & 2.55 & 0.01 & 0.49 & 0.29 & 6.49 & 0.01 \\
Poland & +0.56 & 0.16 & 3.48 & 0.00 & 0.46 & 0.26 & 12.01 & 0.00 \\
Slovakia & +0.61 & 0.21 & 2.94 & 0.00 & 0.60 & 0.36 & 8.78 & 0.00 \\
Hungary & +0.48 & 0.20 & 2.44 & 0.01 & 0.49 & 0.31 & 5.92 & 0.01 \\
\hline
\end{tabular}

Source: own analysis based on BEEPS 2009 data. 
For the companies that use outsourcing, the probability of implementation of international quality certificates was much greater than the probability of implementation of international quality certificates for the companies that do not use outsourcing. Depending on the country, the probability of implementing international quality certificates ranged from 0.46 to 0.60 . The probability was from $58 \%$ to $77 \%$ greater than the probability of implementing international quality systems in companies that did not use outsourcing. Comparing different countries, one notices that the Slovak companies have the highest probability of implementing international quality certificates, whereas the Polish companies have the lowest probability of implementing international quality certificates.

The positive influence of outsourcing on implementation of international quality certificates can be related to the size of supplier network that the company is a part of. In such a setting, the company can instantly gain knowledge of the production-related systems used by other participants of the network which systems they aim to implement in the future. This knowledge is then used to define a benchmark for the outsourcing company and motivates them to implement analogous systems, if these were not in use before.

\section{Influence of Innovative Activity on Outsourcing}

Analysing the influence of innovative activity on outsourcing, obtained 15 probit models, presented in Table 6 and Table 7.

Table 6

Parameter Values With Explanatory Variables Describing the Investment Aspect of Innovative Activity in Companies, in the Probit Models Describing the Occurrence of Outsourcing in Companies From the Visegrád Countries

\begin{tabular}{lllllllrr}
\hline Company's location & parameter & $s$ & $t$ & $p>|z|$ & $p_{1}$ & $p_{2}$ & $x^{2}$ & $p$ \\
\hline Occurrence of investment & & & & & & & & \\
\hline Czech Republic & +0.42 & 0.20 & 2.15 & 0.03 & 0.23 & 0.12 & 4.74 & 0.03 \\
Poland & +0.43 & 0.16 & 2.74 & 0.01 & 0.16 & 0.08 & 7.90 & 0.00 \\
Slovakia & +0.69 & 0.21 & 3.29 & 0.00 & 0.22 & 0.07 & 11.78 & 0.00 \\
\hline R\&D activity & & & & & & & & \\
\hline Czech Republic & +0.54 & 0.20 & 2.77 & 0.01 & 0.29 & 0.14 & 7.59 & 0.01 \\
Poland & +0.78 & 0.14 & 5.39 & 0.00 & 0.27 & 0.08 & 28.97 & 0.00 \\
Slovakia & +0.47 & 0.19 & 2.51 & 0.01 & 0.25 & 0.13 & 6.22 & 0.01 \\
Hungary & +0.62 & 0.19 & 3.30 & 0.00 & 0.30 & 0.12 & 10.73 & 0.00 \\
\hline
\end{tabular}

Source: own analysis based on BEEPS 2009 data.

From the models presented in the above table, it follows that innovative activity also influences the occurrence of outsourcing. The probability of outsourcing in companies active in investment aspects of innovative activity ranged, depending on the aspect, from 0.16 to 0.30 . The probability was two-fold or even three-fold greater than the probability of outsourcing in companies that were not active in the innovative aspects of innovative activity.

The implementation aspect of innovative activity also positively influences the occurrence of outsourcing in companies. The probability of outsourcing in companies that were innovatively active in terms of implementation aspect ranged, depending on location and the specific aspect, from 0.16 to 0.27 . This probability was two-fold or even (in one case) 11-fold greater than the probability of outsourcing in the companies that were not involved in the innovative activity in the implementation aspect 
The results confirm the thesis of Mahnke (2001, pp. 353-379), that the innovatively active companies better cope with problems related to implementation of outsourcing, compared to the companies that are less innovatively active or that are not innovatively active at all. One should keep in mind that the companies that are innovatively active are characterised by higher risk tolerance, compared to the less innovative companies. Whereas outsourcing, from the very definition, is an activity with inherent high levels of risk.

Table 7

Parameter Values With Explanatory Variables Describing the Implementation Aspect of Innovative Activity in Companies, in the Probit Models Describing the Occurrence of Outsourcing in the Companies From the Visegrád Countries

\begin{tabular}{|c|c|c|c|c|c|c|c|c|}
\hline Company's location & parameter & $s$ & $t$ & $p>|z|$ & $p_{1}$ & $p_{2}$ & $x^{2}$ & $\bar{p}$ \\
\hline \multicolumn{9}{|c|}{ Introduction of new products } \\
\hline Poland & +0.58 & 0.15 & 3.81 & 0.00 & 0.18 & 0.07 & 15.53 & 0.00 \\
\hline \multicolumn{9}{|c|}{ Improvement in manufactured products } \\
\hline Czech Republic & +1.41 & 0.41 & 3.42 & 0.00 & 0.23 & 0.02 & 20.37 & 0.00 \\
\hline Poland & +0.64 & 0.19 & 3.29 & 0.00 & 0.16 & 0.05 & 12.49 & 0.00 \\
\hline Slovakia & +0.56 & 0.22 & 2.52 & 0.01 & 0.20 & 0.08 & 6.87 & 0.01 \\
\hline \multicolumn{9}{|c|}{ Implementation of international quality certificates } \\
\hline Czech Republic & +0.49 & 0.19 & 2.55 & 0.01 & 0.27 & 0.14 & 6.49 & 0.01 \\
\hline Poland & +0.50 & 0.14 & 3.49 & 0.00 & 0.22 & 0.10 & 12.00 & 0.00 \\
\hline Slovakia & +0.54 & 0.18 & 2.94 & 0.00 & 0.25 & 0.11 & 8.78 & 0.00 \\
\hline Hungary & +0.44 & 0.18 & 2.44 & 0.02 & 0.24 & 0.12 & 5.92 & 0.01 \\
\hline
\end{tabular}

Source: own analysis based on BEEPS 2009 data.

\section{Conclusions}

Studying the literature, one encounters the opinion that the vertical production load and its modularity are some of the most important distinguishing features of contemporary organisation (Miozzo \& Grimshaw, 2005, pp. 1419-1439). Organisations that use the modular production system can manufacture better products in shorter time. This is possible by dividing the production process into smaller subsystems, which can be created separately but designed to work as a part of a larger system. The benefits of such an arrangement are related to the fact that the suppliers' experience is transferred to the client-company products.

Generally speaking, cooperation between companies can be divided into two types:

(1) vertical—with the neighbouring supply network links, which are suppliers and customers;

(2) horizontal — with competition and various R\&D entities.

Given the above, outsourcing can be considered as an attempt to replace horizontal cooperation (coopetition) with the vertical one. That is, the company which previously was a competitor becomes a supplier.

The results presented here imply that outsourcing has a stimulating effect on innovative activity of a company, both in terms of investment and implementation aspects. Within the investment aspect, the probability of investment ranged, depending on location, from 0.71 to 0.82 , whereas the probability of $R \& D$ activity ranged from 0.45 to 0.55 . Within the implementation aspect, the probability of introducing new product in outsourcing companies equalled 0.45 . The probability of product modernisation ranged, depending on location, from 0.84 to 0.98 . The probability of implementing international quality certificates ranged, 
depending on location, from 0.46 to 0.60 . Greater probability of innovation in companies using outsourcing confirms Hypothesis 1 . Whereas the fact that the probability of improving manufactured goods in companies using outsourcing was almost 1, confirms Hypothesis 3.

Also, the innovative activity, both in investment and implementation, positively influences the occurrence of outsourcing, confirming Hypothesis 2. The probability of outsourcing in innovatively active companies ranged from 0.16 to 0.30 , depending on location and specific aspect of innovation. Relation between innovation and outsourcing indicates that there is a feedback among these variables. It is worth noting however, that the probability of innovative activity among the companies using outsourcing is higher than the probability of outsourcing among the companies that are innovatively active. It seems that the influence of outsourcing on innovative activity is stronger than the influence of innovative activity on outsourcing.

\section{References}

Adeleye, B. C., Annasingh, F., \& Nunes, M. B. (2004). Risk management practices in IS outsourcing: An investigation into commercial banks in Nigeria. International Journal of Information Management, 24(2), 167-180.

Ang, S., \& Cummings, L. L. (1997). Strategic response of institutional influences on information systems outsourcing. Organization Science, 8(3), 235-256.

Argyres, N., \& Liebeskind, J. P. (1999). Contractual commitments, bargaining power and governance inseparability: Introducing history into transaction cost theory. Academic of Management Review, 24(1), 49-63.

Aubert, B. A., Dussault, S., Patry, M., \& Rivard, S. (1999). Managing the risk of IT outsourcing. Proceedings from the 32nd Hawaii International Conference on System Sciences-Organizational Systems and Technology Track, Maui, HI, USA.

Baldwin, L. P., Irani, Z., \& Love, P. E. D. (2001). Outsourcing information systems: Drawing lessons from a banking case study. European Journal of Information Systems, 10, 15-24.

Barthélemy, J. (2003). The seven deadly sins of outsourcing. Academy of Management Executive, 17(2), 87-87.

Benner, M. J., \& Tushman, M. L. (2003). Exploitation, exploration, and process management: The productivity dilemma revisited. Academy of Management Review, 28, 238-256.

Carayannis, E. G. (1999). Knowledge transfer through technological hyper learning in five industries. Technovation, 19, 141-161.

Chesbrough, H. W. (2003). Open innovation: The new imperative for creating and profiting from technology. Boston: Harvard Business School Press.

Christensen, C. M., Verlinden, M., \& Westerman, G. (2002). Disruption, disintegration and the dissipation of differentiability. Industrial and Corporate Change, 11(5), 955-993.

Desouza, K. C., Awazu, Y., \& Jasimuddin, S. (2005). Utilizing external sources of knowledge. KM Review, 8, 16-19.

Espino-Rodriguez, T. F., \& Padro-Robaina, V. (2006). A review of outsourcing from the resource-based view of the firm. International Journal of Management Reviews, 8(1), 49-70.

Fisher, J., Hirschheim, R., \& Jacobs, R. (2008). Understanding the outsourcing learning curve: A longitudinal analysis of a large Australian company. Information Systems Frontiers, 10, 165-178.

Foray, D. (2004). The economics of knowledge. Cambridge: MIT Press.

Grossman, G. M., \& Helpman, E. (2005). Outsourcing in a global economy. Review of Economic Studies, 72, 135-159.

Gulla, U., \& Gupta, M. P. (2009). Deciding information system (IS) outsourcing: A multi-criteria hierarchical approach. Vikalpa, 34(2), 25-40.

Herrmann, A., Tomczak, T., \& Befurt, R. (2006). Determinants of radical product innovations. European Journal of Innovation Management, 9, 20-43.

Hitt, M. A., Ireland, R. D., \& Lee, H. (2000). Technological learning, knowledge management, firm growth and performance: An introductory essay. Journal of Engineering and Technology Management, 17, 231-246.

Hu, Q., Saunders, C., \& Gebelt, M. (1997). Research report: Diffusion of information technology outsourcing: A reevaluation of influence sources. Information Systems Research, 8(3), 288-301.

Jain, R. K., \& Natarajan, R. (2011). Factors influencing the outsourcing decisions: A study of the banking sector in India. Strategic Outsourcing: An International Journal, 4(3), 296-296. 
Khalfan, A. M. (2004). Information security considerations in IS/IT outsourcing projects: A descriptive case study of two sectors. International Journal of Information Management, 24, 29-42.

Lacity, M. C., \& Willcoocks, L. P. (1998). An empirical investigation technology sourcing practices: Lessons from experience. MIS Quarterly, 22(3), 363-408.

Lankford, W. M., \& Parsa, F. (1999). Outsourcing: A primer. Management Decision, 37(4), 310-316.

Levinthal, D., \& March, J. (1993). The myopia of learning. Strategic Management Journal, 14, 95-113.

Loh, L., \& Venkatraman, N. (1992). Diffusion of information technology outsourcing: Influence sources and the Kodak effect. Information Systems Research, 3(4), 334-378.

Mahnke, V. (2001). The process of vertical disintegration: An evolutionary perspective on outsourcing. Journal of Management and Governance, 3, 31-55.

March, J. G. (1991). Exploration and exploitation in organizational learning. Organization Science, 2, 71-87.

McLellan, K. L., Marcolin, B. L., \& Beamish, P. W. (1995). Financial and strategic motivations behind IS outsourcing. Journal of Information Technology, 10(4), 299-321.

Milgrom, P. R., \& Roberts, J. (1995). Complementarities and fit: Strategy, structure, and organizational change in manufacturing. Journal of Accounting and Economics, 19(2-3), 179-208.

Miozzo, M., \& Grimshaw, D. (2005). Modularity and innovation in knowledge-intensive business services: IT outsourcing in Germany and the UK. Research Policy, 34, 1419-1439.

Oslo Manual. (2005). Guidelines for collecting and interpreting innovation data (3rd ed.). Retrieved from http://www.oecd.org/science/inno/2367580.pdf

Quinn, J. B. (2000). Outsourcing innovation: The new engine of growth. Sloan Management Review, 41, 13-28.

Quinn, J. B., \& Hilmer, F. G. (1994). Strategic outsourcing. Sloan Management Review, 35, 43-55.

Silver, M. (1984). Enterprise and the scope of the firm. London: Martin Robertson.

Sull, D. N. (1999). Why good companies go bad. Harvard Business Review, 77, 42-52.

Welfe, A. (2003). Econometrics - The methods and their use. Warszawa: PWE.

Willcocks, L. P. (2010). The next step for the CEO: Moving IT-enabled services outsourcing to the strategic agenda. Strategic Outsourcing: An International Journal, 1(1), 62-66.

Williamson, O. E. (1975). Markets and hierarchies: Analysis and anti-trust implications. New York: Free Press.

Williamson, O. E. (1985). The economic institutions of capitalism: Firms, markets, relational contracting. Macmillan: Londyn.

World Bank., \& European Bank. (2008). A study conducted by the World Bank and the European Bank for reconstruction and development. Retrieved from http://www.enterprisesurveys.org/Methodology

Yang, D. H., Kim, S., Nam, C., \& Min, J. W. (2007). Developing a decision model for business process outsourcing. Computers \& Operations Research, 34(12), 3769-3778. 